\title{
Sustainable Business Strategies and PESTEL Framework
}

\author{
Dr Tomayess Issa \\ Curtin University of Technology \\ GPO Box U1987 \\ Perth WA 6845 \\ 61892667682 \\ Tomayess.Issa@cbs.cutin.edu.au
}

\author{
A/Prof. Vanessa Chang \\ Curtin University of Technology \\ GPO Box U1987 \\ Perth WA 6845 \\ 61892664487 \\ Vanessa.Chang@cbs.curtin.edu.au
}

\author{
Dr Theodora Issa \\ Curtin University of Technology \\ GPO Box U1987 \\ Perth WA 6845 \\ 61892667725 \\ Theodora.Issa@cbs.curtin.edu.au
}

\begin{abstract}
This paper aims to provide a brief review of cloud computing, followed by an analysis of cloud computing environment using the PESTEL framework. The future implications and limitations of adopting cloud computing as an effective eco-friendly strategy to reduce carbon footprint are also discussed in the paper. This paper concludes with a recommendation to guide researchers to further examine this phenomenon.

Organizations today face tough economic times, especially following the recent global financial crisis and the evidence of catastrophic climate change. International and local businesses find themselves compelled to review their strategies. They need to consider their organizational expenses and priorities and to strategically consider how best to save. Traditionally, Information Technology (IT) department is one area that would be affected negatively in the review. Continuing to fund these strategic technologies during an economic downturn is vital to organizations. It is predicted that in coming years IT resources will only be available online. More and more organizations are looking at operating smarter businesses by investigating technologies such as cloud computing, virtualization and green IT to find ways to cut costs and increase efficiencies.
\end{abstract}

Keywords-Sustainable Business Strategy, Cloud Computing, Ethical issues, PESTEL Framework

\section{INTRODUCTION}

Greenfield (2004) argued that, amid the Tyco, Worldcom, and Enron furor, organizations ought to reflect rather than commit to a 'quick fix' or a 'band aid' solution. Past experiences had demonstrated that business solutions which organizations took were usually based on the assumptions that (1) debacle in the financial markets and (2) lose confidence in business stem from failures in the corporate governance system. Goldsmith

\footnotetext{
${ }^{1}$ (An extended version of this paper won 'Best Paper Award' at the The International Conference on Cloud Computing and Virtualization which is organised by Global Science and Technology Forum (GSTF) CCV 2010 held in Singapore 17th - 18th May 2010)
}

and Samson (2006) posit that with the shift in the role of business combined with the changing business environment and growing community concerns, there are increasing pressure for organizations to pursue sustainable development strategies.

Organizations are faced with the challenge of balancing the demands of global competition and sustainable development. Many organizations are investing resources to create organizational strategies to tackle today's business environment (Jacobides 2010). Globalization, technological innovation, regulatory restructuring, demographic shifts, and environmental pressures have all conspired to continually redraw the competitive landscape. Compounded by issues affecting the environment, organizations making business decisions and solutions must take into account their corporate social responsibility instead of focusing solely on the bottom line of generating revenue and increasing profit. While making profit is a priority to all organizations, it is critical that modernday organizations exercise their corporate social responsibility by focusing on people and the planet.

Kolstad (2007) stated that though corporate social responsibility is on the agenda of most major corporations, corporate executives still largely support the view that corporations should maximize the returns to their owners. There are two justification for this, (1) the Friedmanian view that maximizing owner returns is the social responsibility of corporations, and (2) a position voiced by many executives, that corporate social responsibility and profits go together. Executives conclude that there may be good reasons for firms to deviate from a maxim of profit maximization. Valentine and Fleischman (2008) summed up that corporate social responsibility is juxtaposition between ethics program variables and individual job satisfaction which suggest that companies might better manage employees' ethical perceptions and work attitudes.

Banerjee (2010) contends that in order to overcome corporate social responsibility limitations, there is a need to develop more democratic forms of global governance 
of corporations. Banerjee goes on to highlight the need to examine the processes and outcomes of corporate involvement in political and social domains, however, such examination should not be restricted to only the political and social domains, but it should also include all the aspects of the PESTEL framework.

Kleinrichert (2008) asserted that the commitment to corporate social responsibility is a source of power, as well as an ethical practice for corporate endeavors. Kleinrichert concluded that re-establishing strong relationships with the community could be developed by revisiting corporate social responsibility. In practice, managers should support this by publishing the organization's code of ethics and conducts. Chonko and Wotruba (2003) argued that when managers are familiar with the code's content and intentions, the managers' behavior and outlook are positive and they are more thoughtful in their decision-making. Chonko and Wotruba, (2003) in their study explored whether the impact of code familiarity on code usefulness differs in the following ways: (a) under varying conditions of turbulence and (b) between persons with relativist versus idealist personal values. They concluded that perceptions of ethics code familiarity and usefulness decline as business turbulence increases. The decline in familiarity/usefulness was more pronounced for managers with a relativistic ethical orientation. Though there are attempts to introduce codes of ethics to organizations to exercise corporate social responsibility in order to address today's global economy, there is no immediate indication that we are taking advantage of this.

Some scholars, academics and practitioners argue that the design of and training on codes of ethics would address the problems that the society or the global economy is facing. Some researchers indicated that a document that prescribes behaviors is not a code of ethics because it precludes empowerment to make the ethical decisions. Others consider prescriptive documents to be 'best practice' for codes of ethics. Farrell, Cobbin and Farrell (2002) indicated that there is a distinction between prescriptive and inspirational code types, and this classification becomes a focal point on what is the appropriate subject matter for a code of ethics. When designing a code of ethics, organizations are required to consider the usefulness of the code; and later implement the code so that employees are familiar with the business practices. The recent summit in Copenhagen to engage the world on climate change should provoke countries, governments, businesses, communities, and individuals to participate in taking more social responsibilities of the planet. All businesses and professions have very similar code of ethics embracing knowledge, trust, and integrity to uphold the profession. Given the recent publicity of Greenhouse Effect and Climate Change (n.d.), organizations are acutely aware of their corporate social responsibility.

Many organizations today have acted swiftly to incorporate green IT as part of the organizations' business practice. Some of these organizations have incorporated technology that simultaneously offers services and greening facility. Adoption of cloud computing into the organization's business activities is also increasing. Adopting this technology offers various benefits in electric power reduction consumption of IT hardware. Cloud computing promises many technological and sociological benefits, and it is also touted for its ability to address the need for energy efficiency (Stewart \& Kennedy 2009). In a number of recent studies, cloud computing promises to provide better performance, reliability and scalability, for example, Armburst et al. (2009) and Erdogmus (2009). Cloud computing also attract the recognition of being ethically responsible and ensuring that organizations are becoming more sustainable (Newton 2003). As organizations begin to embrace cloud computing as a green IT service, a strategy to incorporate and implement effective cloud computing services is required for all organizations. This strategy must also ensure that professionals who implement cloud computing services have a set of useful code of ethics and conducts; and that they become familiar with the codes to ensure better dealings at all avenues. A number of professionals' ethical code of conduct already exists and organizations ought to re-visit the codes to ensure that they are adhered to. An example is that of the Information Systems (IS) professionals' ethical code of conduct. Oz (1992, p. 431- 432) stated that, "IS professionals in one country do not differ from their colleagues in other countries, and they are all expected to abide by the same standards of practice, regardless of organizational or national affiliation. This is especially true in the reality of a "global village, where computer networks diminish the importance of national borders". In addition, “technology, does not stand 'outside' of society ... but instead, technology - its manufacturers, benefactors, users - is a social phenomenon itself, subject to all the constraints of other social actors. Among these constraints is the notion of social responsibility: You can and will be held accountable for your actions" (Laudon 1995, p. 38).

\section{BENEFITS OF SUSTAINABLE DEVELOPMENT STRATEGIES}

As mentioned earlier, the adoption of the new cloud computing services and technology will assist in the reduction of capital expenditure and carbon footprint (Grossman 2009), highlighting the importance of sustainable corporate responsibility, thus sustainable strategy. Herbert and Erickson (2009) contended that the realization of cloud computing in businesses may eliminate the need for full time help desk and server support. This will have a major influence on reducing the cost and allowing the deployment of these staff into "white collar' roles. This may also give rise to challenges such as compensation for providers who offer services to external users (Buyya et al. 2009).

Newton (2000) in her sketching of a quarter century of progress in business ethics, highlighted the developments of 'stakeholder theory', joining Freeman (1994) in calling to point 
this theory away from slogans and confrontations in favour of 'fine-grained' account of practices in business and ethics. Incorporating sustainable strategy with emerging technologies is becoming the norms in contemporary businesses (Newton 2003). To do this effectively, and deriving from Dyllick and Hockerts (2002) and McDonough-Braungart (2002) models of corporate sustainability Young and Tilley (2006) proposed an integrated model of corporate sustainability which links together six criteria that a sustainable business will need to satisfy. The six criteria are (1) eco-efficiency, (2) socioefficiency, (3) eco-effectiveness, (4) socio-effectiveness, (5) sufficiency and (6) ecological equity. However, further theoretical development is still underway to have an effective integrated approach to apply the six criteria. Erek et al. (2009, p.2) confirmed that "sustainability has been extensively discussed within corporate management under the synonyms of corporate social responsibility (CSR), greening the business eco-efficiency or eco-advantage". To ensure that organizations develop and adhere to a sustainable development strategy, management should consider aspects of value creation that would benefit its employees, users and stakeholders by encouraging all participants to be environmentally and socially responsible corporate citizens.

By the same token Bowen's argument on 'Enron' is much applicable as he says: 'Enron used a materialistic paradigm for decision making rather than a framework based on moral philosophy, such as the normative ethics of deontology or utilitarianism. Materialism, when applied in a business situation, can encourage avarice and greed, as reported by the former-employee sources. Materialism has failed to gain acceptance as a normative approach to ethics because the selfishness upon which it is based is seen by other schools of thought as an inappropriate basis for ethical analysis (Bowen 2010 p. 34).

\section{CLOUD COMPUTING}

Currently various facilities are available on the Internet to allow users to maintain their data and applications by using Internet and central servers, and this service is called Cloud Computing. Cloud Computing "offers the prospect of dramatically increasing your computing power, being able to balance workloads with demand, and paying only for the services you use" (Simon 2010 p.64). While Velte, Velte, and Elsenpeter (2010) promises that cloud computing would reduce costs (if those are operational or capital), allowing IT departments to divert their concentration onto strategic projects. This means users will be renting computers, storage and network capacity on hourly basis from companies who provide this technology on the Internet. This service is available any time and from anywhere across the world. Lawson (2009, p.10) confirms that "cloud computing and flash-based storage, two fast-emerging IT technologies, are driving each other forward as users of Internet-based services like social networks demand near-real-time access to ever growing amounts of data”.

Gilman (2009, p.22) stated that with cloud computing "new products or services can be added without the usual accompanying investment in new infrastructure, training, or software licensing". In addition, Weier (2009, p.40) stated that this technology is also "becoming more of a business function that helps drive efficiencies in building these apps and consuming services via the cloud". Gilman (2009) and Babcock (2009) indicated that as this technology evolves, the services will offer greater storage capacity, faster speed, and more intuitive user interface. In this regard, organizations will benefit from adopting cloud computing services.

\section{PESTEL FRAMEWORK AND TRIPLE BOTTOM LINE}

In order to gauge the effectiveness of adopting cloud computing in organizations, the main research question to be asked is "Why would organization consider the adoption of cloud computing services and technology?" In order to discuss this research question, the PESTEL framework of political, economic, social, technological, environmental and legal will be used to analyze the adoption of cloud computing and its impact of the triple bottom line. The PESTEL framework is a "mnemonic used in strategic management to group macro-environment factors to help strategists look for sources of general opportunity and risks" (Witcher \& Chau 2010, p.91). The PESTEL framework analyzes the external business environment to understand the 'big picture' in which the organization operates thus enabling them to take advantage of the opportunities and minimize the threats faced by the organization's business activities (Mind Tools, n.d.). In this regard, the PESTEL analysis is used in this research to allow the organizations to understand the big picture of adopting cloud computing in the business environment and to realize the advantages, opportunities and to minimize the threats of this technology.

The analysis of the PESTEL framework and sustainable business strategies are provided in the following section.

\subsection{Political}

The political factor is concerned with government regulations and legal issues that organizations must adhere to. From the political perspective, organizations must consider laws and regulations for their own countries. As cloud computing is distributed with readily available data, the access, and the use of these services may evolve into borderless jurisdiction in the cloud; and organizations need to separate its business dealings and functions from its legal implications. As data stored within a cloud can be stored in different countries, and may be transmitted to computers 
in different geographic locations, the information may be subject to the laws of the specific location of the physical computer that holds the data. As recently reported, "countries like China and the United States are making laws that are having a negative ripple effect on the development of the global cloud, and thus a negative effect on the enrichment of the global economy" (Poston 2008). The same report and in another source (Baker 2008, p.5) claimed that the Canadian government has asked organizations "not to use computers in the global network that are operating within United States borders because the Canadian data stored on those computers could conceivably be negatively impacted by the repercussions of the Patriot Act".

\subsection{Economic}

The economic factor is concerned with the costrelated matters for the organization (Witcher \& Chau 2010). From an economic perspective, organizations that adopt cloud computing for their business activities will expect a reduction in their capital expenditure. As corporate executives have a responsibility in maximizing returns to their owners, new technologies such as cloud computing may alleviate the tight budget of any organizations. As pointed out by Hickey (2010), the "research points to government interest in software-as-a-service solutions, cloud computing, virtualization and social networking initiatives as evidence of the need to meet the dual goals of containing costs and modernizing technology". While cloud computing requires very little capital investment, businesses will incur organizational costs in the form of payment for a cloud computing provider's service. The methods of payment vary, but they can be categorized into two types: utility-based and subscription-based. Under the utility-based method, businesses will only be required to pay for cloud computing resources that they utilize (Hamm 2008). On the other hand, a subscription-based payment involves a predetermined amount of money to be paid on a monthly or annual basis (Salesforce.com, n.d.). A sustainable business strategy must also be developed to ascertain that credible providers are selected to provide the cloud services. If a credible provider provides alternative to the organization's internal platforms and applications - one that requires no capital outlays, long-term contracts, data-center infrastructure or internal IT staff - users can scale the service up or down according to their business needs. Clearly, cloud computing — as a purely on demand servicedelivery model — "is tailor-made for a bubble economy" (Kobielus 2008, p.22).

\subsection{Social}

The social factor is related to changes to the enterprises by adopting the cloud computing technology. The social aspect includes consumer awareness, citizens' attitudes and individual practices of using services on the cloud. Organizations and employees must adhere to a set of guiding principle or code of ethics; and to be aware of the value of information stored on the cloud, e.g. the value of personal information, disclosure of personal information and uses of personal data. Privacy issues and different level of data sensitivity (e.g. financial data, payroll/HR data, employment history, medical history, etc) must also be considered when implementing the use of cloud services. In addition to the above aspects, culture within the organization also forms part of this factor. The transition to cloud computing may affect employee's job security as management decide to strategize further costs cutting and its effects on employee morale may be detrimental to securing future profit. It is important that executive consider this aspect as part of the business sustainable development plan.

\subsection{Technological}

In addition to cutting capital expenses, adopting cloud-computing technology has many advantages, for example the availability, durability, flexibility and mobility of the cloud provide infinite data resources and storage (Jha, Merzky \& Fox 2009, p.1093). Users are able to access information conveniently on demand at anywhere and anytime. The unit cost for cloud-based "services is often lower than the cost if the services were provided directly by the organization itself" (Grossman 2009, p.25). Furthermore, cloud computing "resources can be purchased with optional funds, rather than as a capital expenditure" (Smith 2009, p.67), and users do not wait for the installation and implementation of their equipment since this technology is readily available online. This technology provides outstanding performance at maximum cost and "company can always shift its business to another company offering better service or lower prices" (Smith 2009, p.67).

\subsection{Environmental}

With growing sensitivity toward environmental issues, companies are increasingly expected to 
take greater responsibility for making sustainable development a reality. However, defining this new role is a major challenge for companies as they search for ways to balance economic, environmental and social performance. To integrate sustainability principles into their business strategies and to aid resource allocation decisions, managers must quantify the link between environmental actions and financial performance. Epstein and Roy (2003) have proposed a framework that might assist managers in making the 'business case' for sustainability initiatives. Within the context of that framework, they examined a sample of corporate sustainability reports to (1) determine whether companies have been measuring the financial impact of environmental and social initiatives, (2) identify specific areas of concern and obstacles to the integration of sustainability into corporate performance and (3) provide specific guidance as to how companies can move toward a better integration of environmental and social initiatives in their decision-making processes and operations. The results suggested that companies are increasingly attempting to link environmental initiatives to financial performance. While environmentally responsible organizations are aware of the hypes surrounding cloud computing and climate change, green energy and related topics, many organizations are yet to commit to a clear business case for the broader issue of sustainability.

\subsection{Legal}

One of the biggest concerns is the storage of sensitive data (i.e. customer information, employee records) on the cloud, which warrants ethical and privacy considerations. Users are concern if their "sensitive data were to fall into the wrong hands" (Preston 2008, p.52). A number of business decisions had considered security in the cloud as the top reason that holds back many from using the cloud (Barman 2008, p.35). From an ethics point of view, a company that stores data in a cloud computing provider's data center gives rise to the possibility for the provider to access or tamper with company data. Likewise, from a privacy point of view, storing customer information and employee records on the cloud may put a company at risk for possible legal action if that information is made public or is used in an otherwise unauthorized manner. The use of computing best practice such as data migration with strong authentication and guiding principles of IT use should continue to apply in the cloud (McGarvey 2008, p.11). Organizations must also consider service-level agreements (SLAs) with cloud computing services providers. If there is a security failure in the cloud that may compromise users' data, the organization must comply legally to notify users under state or federal law (Chong et al. 2009). Protection of Intellectual Property (IP) must also be considered in cloud computing.

It is an attempt in this paper to introduce the services and technology of cloud computing to be a critical part of the triple bottom line. The "triple-bottom line" concept provides a framework for companies to measure and report their performance and organizational success in relation to the three pillars of 'people, planet, and profit'. The primary objective of a corporate sustainability program is to account for the triple bottom line. Erek et al. (2009) stated that corporate sustainability is about minimizing a business' negative impacts on people, societies and the environment while maintaining or enhancing value for customers, business partners and shareholders. From the business perspective, "sustainability is mainly equated with the economical or financial sustainability. However, integrated corporate sustainability is achieved by recognizing the interdependence of the three dimensions over time and keeping an optimal balance between them" (Erek et al. 2009, p.2).

Many people are skeptical of organizations that claim to implement the triple-bottom line that encompasses caring for the environment... Some of the negativity surrounding this is the perception that executives may have been tainted with the importance of profit. Alexander (2007) contends that there is a systemic condition inherent in contemporary markets that compel managers not to pursue more morally preferred initiatives if those initiatives require actions that conflict with profit maximization. To overcome this constraint Alexander (2007) argues we must elevate a more normatively preferable value with ideal environmental sustainability, to the level of being the primary filtering value through which other competing values are evaluated, prioritized, and implemented. In order for this to occur in practice, the individual and organization's ethics must be uphold and a change must also be made relative to the laws, rules, and regulations that define and guide the market.

Elliot (2007, p.106) stated the Australian national government policy encourages triple bottom line reporting one government agency 
expressed concern that "effective triple bottom line reporting could not be undertaken until the ICT industry makes available better information to support government reporting requirements." Triple bottom line reporting remains voluntary for Australian Government agencies. Currently the Australian government is working very closely with a high level of ICT and stakeholders across the states to consider "how to better manage and reduce the environmental impacts, including energy consumption, from using ICT" (Elliot 2007, p.104). However, it is up to the ICT industry to "address environmental considerations for manufacturing, product use, design and disposal" (Elliot 2007, p.104).

\section{CONCLUSION}

This article discussed the concepts and benefits of cloud computing in organizations. It is anticipated that this technology would have positive aspects and a direct impact on sustainability especially in reducing organizations' carbon footprint. Although many organizations embrace social responsibility, are aware of climate change and green IT, many are yet to explore this technology. To ensure that cloud computing is well implemented; organizations need to consider a plan to incorporate sustainable development as major part of their organization's strategy.

An honest examination of organizational ethics needs to be conducted to ensure that those responsible on strategy development maintain the necessary knowledge, abilities and stamina to tackle the issues of the triple bottom lines. In this respect, Bowen (2010) contends that a critical component of organizational ethics and ethical paradigms should begin with individual executives. Executives' ethical decision-making abilities and ethical mindsets would govern the success or failure of these codes of ethics.

In this article, PESTEL framework was used to analyze some of the issues encircling the adoption of cloud computing services and technology. Not only that there is urgency for corporations to be environmentally savvy, but there is also an urgent need for institutions and academics to join in the cause to prepare and educate the future generations. There are scholars who recognize the importance of such issues, providing empirical evidence of recent focus on business ethics including sustainable development, others propose that universities need to incorporate principles of social sustainability in the planning and change management policies and processes. Those students are the leaders of the future, thus need to be educated to be the force for change in the organization, and society as a whole. As a start, we will be trialing a course that will be offered to post graduate students on the environmental, economic, and social benefits of cloud computing in organizations, and in the future, a similar course will be offered to the industry to encourage the adoption of cloud computing in their businesses.

\section{REFERENCES}

[1] Alexander, J 2007, 'Environmental Sustainability Versus Profit Maximization: Overcoming Systemic Constraints on Implementing Normatively Preferable Alternatives', Journal of Business Ethics, vol. 76, no. 2, pp. 155-62. Springer 2007.

[2] Armbrust, M, Fox, A, Griffith, R, Joseph, AD, Katz, R, Konwinski, A, Lee, G, Patterson, D, Rabkin, A, Stoica, I \& Zaharia, M 2009, Above the Clouds: A View of Cloud Computing. Retrieved 1 Dec 2009, from http://radlab.cs.berkeley.edu/w/uploads/2/24/9 _ Above the CloudsA View of Cloud Computing .pdf

[3] Babcock, C 2009, 'Hybrid Clouds', Information Week, vol. 1240, p. 15. ABI/INFORM Global.

[4] Baker, P 2008, The Cloud: Saving Grace or Empty Thunder? , Internet. com.

[5] Banerjee, SB 2010, 'Governing the Global Corporation: A Critical Perspective', Business Ethics Quarterly vol. 20, no. 2, pp. 265-74.

[6] Barman, B 2008, 'Safe on the Cloud', in Siliconindia, pp. 34 - 5.

[7] Bowen, SA 2010, 'Almost a decade later: Have we learned lessons from inside the crooked E, Enron?', Ethical Space: The International Journal of Communication Ethics, vol. 7, no. 1, pp. 28-35.

[8] Buyya, R, Yeo, CS, Venugopal, S, Broberg, J \& Brandic, I 2009, 'Cloud Computing and emerging IT Platforms: Vision, hype, and reality for delivering computing as the 5th utility', Future Generation Computer Systems, vol. 25, pp. 599 - 616 .

[9] Chong, F, Miguel, A, Hogg, J, Homann, U, Zwiefel, B, Garber, D, Joseph, J, Zimmerman, S \& Kaufman, S 2009, Design Considerations for $S+S$ and Cloud Computing. Retrieved 1 March 2010, from http:// msdn.microsoft.com/en-us/architecture/aa699439.aspx

[10] Chonko, LB \& Wotruba, TR 2003, 'Ethics code familiarity and usefulness: Views on idealist and relativist managers under varying conditions of turbulence', Journal of Business Ethics, vol. 42, no. 1. ABI inform.

[11] Dyllick, T \& Hockerts, K 2002, 'Beyond the business case for corporate sustainability', Business Strategy and the Environment, vol. 11, no. 2, pp. 130-41.

[12] Elliot, S 2007, 'Environmentally Sustainable ICT: A Critical Topic for IS Research?', Pacific Asia Conference on Information Systems, pp. $100-12$.

[13] Epstein, MJ \& Roy, M-J 2003, 'Making the Business Case for Sustainability: Linking Social and Environmental Actions to Financial Performance', The Journal of Corporate Citizenship, no. 9, pp. 7996.

[14] Erdogmus, H 2009, 'Cloud Computing: Does Nirvana Hide Behind the Nebula?', IEE Software, vol. 26, no. 2, p. 4.

[15] Erek, K, Schmidt, N-H, Zarnekow, R \& Kolbe, LM 2009, 'Sustainability in Information Systems: Assortment of Current Practices in IS Organizations', Americas Conference on Information Systems (AMCIS), pp. 1-9.

[16] Farrell, BJ, Cobbin, DM \& Farrell, HM 2002, 'Codes of ethics: Their evolution, development and other controversies', Journal of Management Development, vol. 21, no. 2, pp. 152-63.

[17] Freeman, ER 1994, 'The Politics of Stakeholder Theory: Some Future Directions', Business Ethics Quarterly, vol. 4, pp. 409-21.

[18] Gilman, R 2009, 'Cleaning Confusion on Cloud Computing', American Agent \& Broker, vol. 81, no. 9, p. 22. ABI/INFORM Global.

[19] Goldsmith, S \& Samson, D 2006, Sustainable Development and Business Success, Thomson, Melbourne.

[20] Greenfield, WM 2004, 'Attention to people and principles is key to corporate governance and ethics', Employment Relations Today, vol. 30, no. 4, pp. 1-10. ABI/INFORM Global.

[21] Grossman, RL 2009, 'The Case for Cloud Computing', Computer.org/ ITPro, pp. $23-7$.

[22] Hamm, S 2008, Cloud Computing: Eyes on the Skies. Retrieved 1 March 2010, from http://www.businessweek.com/magazine/ content/08 18/b4082059989191.htm

[23] Herbert, L \& Erickson, J 2009, The ROI Of Software-As-A-Service, Forrester. 
[24] Hickey, K 2010, Study gauges interest in cloud computing, green IT. Retrieved 1 March 2010, from http://gcn.com/Articles/2010/02/16/ Study-gauges-interest-in-cloud-computing-green-IT.aspx

[25] Jacobides, M 2010, 'Strategy Tools for a Shifting Landscape', Harvard Business Review, vol. 77, no. January/February, pp. 77 - 84.

[26] Jha, S, Merzky, A \& Fox, G 2009, 'Using Clouds to Provide Grids with Higher levels of Abstraction and explicit support for usage modes', Concurrency Computat: Pract. Exper, vol. 21, pp. 1087 -108.

[27] Kleinrichert, D 2008, 'Ethics, Power and Communities: Corporate Social Responsibility Revisited', Journal of Business Ethics, vol. 78, pp. $475-85$.

[28] Kobielus, J 2008, 'Cloud Computing in a Bubble Economy', in Networkworld.com, p. 22, 15 December 2008.

[29] Kolstad, I 2007, 'Why Firms Should Not Always Maximize Profits', Journal of Business Ethics, vol. 76, pp. 137-45. Springer 2007.

[30] Laudon, KC 1995, 'Ethical Concepts and Information Technology', Communications of the ACM, vol. 38, no. 12, pp. 33 - 9.

[31] Lawson, S 2009, 'The Cloud Could Be a Boon for Flash Storage', ComputerWorld, vol. 43, no. 26, p. 10. ABI/INFORM Global.

[32] McDonough, W \& Braungart, M 2002, 'Design for the triple top line: new tools for sustainable commerce', Corporate Environmental Strategy, vol. 9, no. 3, pp. 251-8.

[33] McGarvey, R 2008, Three Steps to Secure Cloud Computing, Internet. com.

[34] Newton, LH 2000, 'Millennial Reservations', Business Ethics Quarterly, vol. 10, no. 1, pp. 291-303.

[35] Newton, LH 2003, Ethics and Sustainablity, Sustainable Development and the Moral Life, Prentice-Hall, Inc., New Jersey.

[36] Oz, E 1992, 'Ethical Standards for Information Systems Professionals:
A Case for a Unified Code', MIS Quarterly, vol. 16, no. December, pp. $423-33$.

[37] Poston, L 2008, Computers Without Borders: Cloud Computing and Political Manipulation. Retrieved 15 Dec 2009, from http://profy. com/2008/05/25/cloudcomputingpolitics/

[38] Preston, R 2008, 'Will Cloud Computing Rain On IT's Parade?', Information Week, vol. 1173, p. 52.

[39] Simon, P 2010 The Next Wave of Technologies, John Wiley \& Sons USA.

[40] Smith, R 2009, 'Computing in the Cloud', ed. RT Management. Industrial Research Institute, Inc., pp. 65 - 8.

[41] Stewart, E \& Kennedy, J 2009, The Sustainability Potential of Cloud Computing: Smarter Design. Retrieved 1 Dec 2009, from http://www. environmentalleader.com/2009/07/20/the-sustainability-potential-ofcloud-computing-smarter-design/

[42] Valentine, S \& Fleischman, G 2008, 'Ethics Programs, Perceived Corporate Social Responsibility and Job Satisfaction', Journal of Business Ethics, vol. 77, no. 2, pp. 159 - 72.

[43] Velte, AT, Velte, TJ \& Elsenpeter, R 2010, Cloud Computing - A Practical Approach McGraw Hill, USA.

[44] Weier, MH 2009, 'SaaS Leader Practices What It Preaches', Information Week, vol. 1241. ABI/INFORM Global.

[45] Witcher, BJ \& Chau, VS 2010, Strategic Management Principles and Practice, Cengage Learning EMEA, United Kingdom.

[46] Young, W \& Tilley, F 2006, 'Can Businesses Move Beyond Efficiency? The Shift toward effectiveness and Equity in the Corporate Sustainability Debate', Business Strategy and the Environment, vol. 15, pp. 402-15. InterScience. 


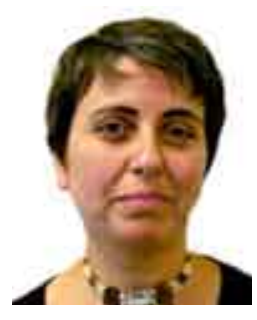

Dr Tomayess Issa is a Lecturer and Postgraduate Course Leader at the School of Information Systems at Curtin University of Technology. Her research interests include teaching usability and Human Computer Interaction, networking, Social networking, information systems, web design, and more recently cloud computing. In addition, she is interested in establishing teaching methods and styles to enhance the students' learning experiences and problems that students face.

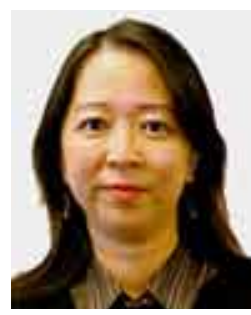

Associate Professor Vanessa Chang is currently the Head of School of Information Systems at the Curtin Business School, Curtin University of Technology. Her research interests include Global IT Management, IT Governance, Business Process Management, Cloud Computing, and Green IT. In addition, her research interests also cover areas of e-learning environments, virtual worlds and Web 2.0. She has experience in consulting and teaching in Information Technology Management, IT Planning, Business Systems Analysis, Object-Oriented Analysis, and Agile Development Methodologies.

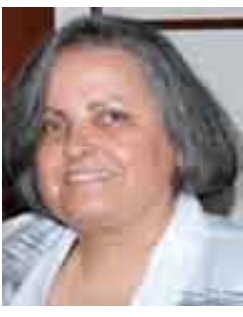

Dr Theodora Issa is currently a Lecturer at the School of Management, Curtin University of Technology. Theodora's engagement to higher education started with teaching at the School of Information Systems in the areas of Web Design and Problem Analysis, during which period she supervised students who implemented industrybased Information Systems Projects. Her research interests include teaching, online teaching, and learning, ethical mindsets, spirituality, aesthetic judgment, more recently sustainable development and business strategy that ignited her interest in cloud-computing. 